Reviews

\author{
Erikson, $\mathrm{K}$. \\ 1994. A New Species of Trouble: The Human Experience of Modern Disasters. New \\ York: Norton. \\ Hoffman, S. \\ 1998. "Eve and Adam Among the Ashes. In E. Enarson and B. Morrow, eds. The \\ Gendered Terrain of Disaster: Through Women's Eyes, pp. 55-61. Westport, CT: \\ Greenwood. \\ Hoffman, S. \\ 1999. "The Worst of Times, the Best of Times: Toward a Model of Cultural Response to \\ Disaster," In A. Oliver-Smith and S. Hoffman, eds., The Angry Earth: Disaster in \\ Anthropological Perspective, New York: Routledge. \\ Oliver-Smith, A. \\ 1992. The Martyred City: Death and Rebirth in the Andes. Prospect Heights Il: \\ Waveland. \\ Peacock,W, B. Morrow and H. Gladwin. \\ 1998. Hurricane Andrew: Ethnicity, Gender, and a New Sociology of Disaster. London: \\ Routledge.
}

\title{
Human Demography and Disease, by Susan Scott and Christopher Duncan (1998) New York: Cambridge University Press. 354 pp.
}

\section{Reviewed by Robert D Hoppa, Department of Anthropology, University of Manitoba, Winnipeg, Manitoba, Canada}

Human Demography and Disease represents what I believe to be a much welcome and much needed addition to the broad field of historical demography. As a reference work or teaching manual for quantitative methods for analysing historical demographic data, the book is excellent. Drawing heavily from their own research on epidemic diseases and time series analysis of parish records, the authors present a series of case studies to illustrate the application, methods, and interpretation of various statistical approaches to understanding the relationships between mortality, disease and environment (e.g. weather, economic conditions etc) over long periods of time. While their case studies are very specific, for the most part they are easily transferable to other kinds of analyses that individuals might be interested in.

This book is not for the total novice, however. In places it becomes extremely technical and requires a solid grasp of the material within the chapters. All the same, its technical depth is what makes the volume most useable as both a reference work for individual researchers and a training manual for courses in quantitative history, historical demography or related topics like population ecology/historical geography or epidemiology. 


\section{Reviews}

The first two chapters of the book essentially provide an introduction to the general subject areas and the sources of analysis. Chapter 1 provides an extremely brief and generalized overview of the fundamental relationship between mortality and morbidity in populations, and acts as a backdrop for demonstrating the very broad readership that this book is geared to. Chapter 2 is also an introductory chapter, but here presenting some comments on the principal source of data most readers will be using (parish records) and the principal methodological approach explored throughout the book ö time series analysis. This chapter sets the overall tone for the volume, and in my opinion is the litmus test for readers. If you shy away from the book after reading this brief chapter, this book probably isn't for you. However, I suspect that for many readers like myself, reading Chapter 2 will result in a response along the lines of "Hey, that's what I'd like to be able to do with my data. Let's see how this works."

The next eleven chapters provide illustrations of various aspects of time series analysis for historical demography. While they appear at first glance somewhat modular in structure, this is in fact a strength of the book. Each chapter contains numerous cross-references to either previous or forthcoming chapters, and because each deals with a specific analytical approach, many people will find that they are able to jump to individual chapters that are more directly relevant to their own research questions and the type of analysis they would like to undertake.

Of key importance in this book is the idea of short wavelength versus long wavelength oscillations in historical demographic data. Understanding and interpreting these differences form the basis of Chapters 3 through 8 . Chapter 3 provides an introduction to the anatomy of time series analysis using a familiar and relatively standard data type.

In this way, it is an extremely useful chapter for those not familiar with time-series analysis. Specifically, this chapter introduces the concept of intrinsic versus extrinsic mortality cycles. While much of the later chapters increase in complexity, Chapter 3 provides a solid introduction that acts as a foundation on which subsequent chapters build. Chapters 4 and 5 explore one of the real advantages of mathematical epidemiology for historical demography ö the ability to model population processes and then compare model prediction or outcomes to observable outcomes from the data themselves. Chapters 6 through 8 provide a series of illustrations for understanding the impact of short-wave or exogenous mortality cycles (grains prices, wool prices) and their interactions with the general demographic features of a population (fertility rates, infant mortality etc) and long-wave or exogenous cycles associated with epidemic diseases. One of the nice features of this book is again illustrated in this section whereby subsequent chapters continue to build on evidence presented in previous case studies, while at the same time remaining independent enough for use as individual methodological references.

Chapters 9 through 13 present a series of cases studies focused primarily on smallpox, measles and Whooping Cough in London, to illustrate various approaches to modelling disease processes in historical populations. These are probably the most rigorous chapters for the nonspecialist as they provide a series of in-depth illustrations of the power of mathematical epidemiology for addressing historical demographic questions. Key issues addressed include interepidemic interval, changes in age-specific susceptibility, population structure, the effects of codependent variables like temperature or nutrition and even interactions among multiple diseases. The latter is particular relevant as too often analyses model the impact of specific diseases independent of one another. While this adds to computational ease it is an undesirable approach since we know that causes of death do not operate independently of one another.

Chapter 14 presents a large-scale illustration of the analytical techniques presented in the previous 5 chapters. This forms as a lead-in to the final chapter that argues succinctly for the power of time-series methods for meta-analyses in historical demography. Here the authors reiterate that one of the strengths of the techniques presented in this volume is the ability to differentiate endogenous mortality cycles related to broader interactions of demographic structure versus exogenous mortality cycles that can be detected independently, but likely have interactions with other changes socio-economic factors.

Overall, the book is highly recommended to anyone interested in learning more quantitative 
Reviews

approaches to disease-mortality-environment interactions in historical demographic data. Useable as both a reference source and a teaching manual, it will serve as an invaluable research tool for historical demographers, quantitative historians, historical geographers, historical epidemiologists, and related specialists.

\section{Coalitions Across the Class Divide: Lessons from the Labor, Peace, and Environmental Movements, by Fred Rose. Ithaca: Cornell University Press (2000), xi, 253 pp.}

\section{Reviewed by Vincent Lyon-Callo, Department of Anthropology Western Michigan University.}

Large, organized, public demonstrations recently confronted meetings of the World Trade Organization in Seattle, the World Bank in Washington, and the Organization of American States in Ottawa. Thousands of activists used the meetings as a platform for articulating critiques of neoliberal social policies, environmental degradation, and rising global inequities. They also used the meetings as a possible springboard for building progressive, international collaborative efforts between environmental, labor, and peace organizations. Receiving less attention, but important nonetheless, similar collaborations are currently being negotiated every day in communities across the United States in "living wage." Jobs with Justice, and environmental justice campaigns.

As indicated by these recent collaborative efforts, it appears that progressives are increasingly aware that they need to work together to have any hope to challenge emergent free trade policies and stem the tide of increasing corporate control of the social and the environment. That is precisely the thesis of Fred Rose's Coalitions Across the Class Divide. As Rose argues, "the major crises that each movement faces are inherent in the emergent free trade regime. Global corporate mobility has shifted the balance of power away from workers and unions. National sovereignty over environmental regulations is being ceded to international trade tribunals" (112). He suggests that the primary political challenge for progressives today is to foster a more inclusive politics to effectively resist the increasing corporate and elite control over the political, economic, and environmental landscape of the nation.

However, Rose does much more in this timely and important new book than simply call for collaborative efforts between labor and environmental movements. As Rose points out, significant barriers continue to foster possible divisions between peace, labor, and environmental activists despite the recent nascent efforts. He analyzes both the potentiality of such coalitions and the complex set of barriers serving as obstacles to be overcome. Rose argues that one of the major barriers to effective collaborative resistance occurs when labor and environmental movements remain entrenched in "identity" or "interest group" politics, thus creating a political choice between jobs or a healthy environment. He suggests that within the framework of the United States, political and economic elites need to craft alliances with other social groups to advance their goals. This is made much easier when environmental, labor, and peace movements see their agendas as being in conflict with one another. Rose thus suggests that "powerful interests are served by pitting citizens and their legitimate issues against each other" (8) in such ways. He discusses how this occurs by examining recent struggles in the forest of the Pacific Northwest as well as economic restructuring and military conversion efforts in Maine, Washington, and Minnesota.

Through his ethnographic case studies, Rose suggests that a primary barrier to effective collaborative resistance is that single interest group movements (such as labor, peace, environmental, racial justice, feminist, and so forth) tend to attract members who are very similar in terms of class, race, educational level, and other indicators of social background. Very often 